\title{
Avaliação de produtividade através da aplicação via foliar de azospirillum brasilense na cultura de milho
}

Diante da necessidade de se obter técnicas alternativas para aumento de produtividade de milho economicamente viável, a utilização do Azospirillum brasilense tem se mostrado uma alternativa sustentável e promissora, assim no presente estudo, objetivou-se determinar a melhor dose de Azospirillum brasilense via aplicação foliar, produtividade e a relação de custo de produção. Para isso foram realizados tratamentos com diferentes dosagens de Azospirillum brasilense e adubação mineral complementar, onde o delineamento experimental realizado constituiu-se de 5 blocos com 4 tratamentos. Com os resultados foi possível observar que com o aumento de doses, ocorre também um aumento da produtividade em relação a testemunha, sendo possível concluir que a dose ótima de aplicação foi $114,75 \mathrm{~mL}$ ha-1. A relação de custo produtividade a partir da dose $107 \mathrm{~mL}$ ha-1 tendeu-se a estabilizar, sendo assim, o que resulta na conclusão de que qualquer dosagem acima desta se encontra dentro da mesma faixa de custo. Assim recomenda-se a dosagem ótima de $114,75 \mathrm{~mL}$ a ser utilizada tanto para o acréscimo da produtividade bem como para a lucratividade do produtor rural. A utilização da bactéria se mostrou como uma tecnologia tecnicamente viável, sustentável, capaz de minimizar danos ao meio ambiente, além de proporcionar redução de custos ao produtor rural com insumos químicos.

Palavras-chave: Agricultura sustentável; Produtividade; Zea mays.

\section{Evaluation of productivity through the application by foliar application of azospirillum brasilense in corn culture}

\begin{abstract}
In view of the need to obtain alternative techniques to increase productivity of economically viable maize, the use of Azospirillum brasilense has shown to be a sustainable and promising alternative, so in the present study, the objective was to determine the best dose of Azospirillum brasilense by foliar application, productivity and cost of production ratio. For this, treatments with different dosages of Azospirillum brasilense and complementary mineral fertilization were carried out, where the experimental design consisted of 5 blocks with 4 treatments. With the results, it was possible to observe that with the increase of doses, an increase in productivity in relation to the control also occurred, and it was possible to conclude that the optimum application rate was $114.75 \mathrm{~mL}$ ha- 1 . The costproductivity ratio from the $107 \mathrm{ml}$ ha -1 dose tended to stabilize, thus resulting in the conclusion that any dosage above this is within the same cost range. Thus, the optimal dosage of $114.75 \mathrm{~mL}$ is recommended to be used both for the increase of productivity as well as for the profitability of the rural producer. The use of the bacterium proved to be a technically feasible, sustainable technology capable of minimizing damages to the environment, besides providing cost reduction to the rural producer with chemical inputs.
\end{abstract}

Keywords: Sustainable agriculture; Productivity; Zea mays.

Topic: Ciências do Solo

Reviewed anonymously in the process of blind peer.
Diego César Veloso Rezende (1D)

Instituto Federal Goiano, Brasil

http://lattes.cnpq.br/2390623769547865

http://orcid.org/0000-0001-6176-0220

diegoformiga@yahoo.com.br

Éllen Lemes Silva (iD)

Instituto Federal Goiano, Brasil

http://lattes.cnpq.br/2020996967548069

http://orcid.org/0000-0001-5649-5055

ellen cbba@hotmail.com

Ana Flávia de Jesus Pinto (iD)

Instituto Federal Goiano, Brasil

http://lattes.cnpq.br/6338082904943098

http://orcid.org/0000-0001-9539-0344

anaflaviah15@gmail.com

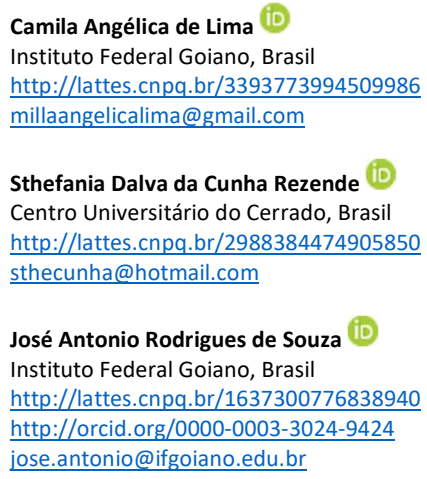

\author{
Débora Astoni Moreira (iD \\ Instituto Federal Goiano, Brasil \\ http://lattes.cnpq.br/0892554192927049 \\ http://orcid.org/0000-0002-8658-1269
} debora.astoni@ifgoiano.edu.br
Referencing this:

REZENDE, D. C. V.; SILVA, É. L.; PINTO, A. F. J.; LIMA, C. A.; REZENDE, S. D. C.; SOUZA, J. A. R.; MOREIRA, D. A.. Avaliação de produtividade através da aplicação via foliar de azospirillum brasilense na cultura de milho. Revista Ibero Americana de Ciências Ambientais, v.9, n.7, p.25-33, 2018. DOI: http://doi.org/10.6008/CBPC21796858.2018.007.0003 


\section{INTRODUÇÃO}

O milho é um dos principais cereais cultivados no mundo (CALDARELLI, 2012). O Brasil é o terceiro maior produtor mundial de milho, obtendo uma produtividade média na safra 2016/2017, em torno de $5.556,0 \mathrm{~kg} \mathrm{ha-}{ }^{-1}$ (CONAB, 2017), considerada baixa quando comparada com os principais produtores como Argentina e EUA que produziram respectivamente $7.000 \mathrm{~kg} \mathrm{ha}^{-1} \mathrm{e} 10.719 \mathrm{~kg} \mathrm{ha}^{-1}$. Em relação a exportação no ano de 2017, o Brasil exportou um total de 29,25 milhões de toneladas de milho, sendo um volume recorde (MDIC, 2018). Contudo espera-se que na safra 2017/2018 haja uma redução na produção chegando somente a $5.059 \mathrm{~kg} \mathrm{ha}^{-1}$ (CONAB, 2018).

Sua importância econômica está relacionada ao seu alto potencial produtivo, composição química e valor nutricional de seus grãos, bem como as diversas formas de utilização na alimentação humana e animal, além de ser fonte de matéria-prima para a indústria (MEIRA et al., 2009; CARVALHO et al., 2011; SOUZA et al., 2012; SOUZA, 2017).

A baixa fertilidade dos solos e os custos altos acarretados devido á fertilização nitrogenada, tem estimulado a busca por alternativas de baixo custo e sustentáveis, bem como ganhos de produtividade com menor área cultivadas, obtendo um alimento de qualidade com a capacidade de atender a demanda do produto (DOTTO et al., 2010; COSTA et al.,2012). O nitrogênio é um dos nutrientes que apresentam os efeitos mais expressivos no aumento da produção dos grãos de milho; constituinte das moléculas de proteínas, enzimas, coenzimas, ácidos nucléicos e citocromos, além de ser integrante da molécula de clorofila (GROSS et al., 2006; VALE et al., 2015).

O milho é considerado uma das culturas mais exigentes em nutrientes, sendo o nitrogênio $(\mathrm{N})$ um requisito importante para o crescimento e desenvolvimento da planta (ROMUALDO et al, 2018). As plantas são capazes de acumular cerca de $22 \%$ de N no estádio V3, atingir $60 \%$ em V6 e extrair $74,6 \mathrm{~kg} \mathrm{ha}^{-1}$ em V10 (Von PINHO et al., 2009; ROMUALDO et al., 2018). Dentre as alternativas ecológicas que auxiliam no aumento da eficiência de produção, destaca-se a fixação biológica de nitrogênio atmosférico (FBN), realizada por bactérias diazotróficas, auxiliando na redução da aplicação de insumos e o melhor aproveitamento destes (VOGEL, 2013).

O uso de inoculantes à base de bactérias do gênero Azospirillum spp., podem induzir efeitos positivos no crescimento das plantas quando dosados adequadamente (CAVAGLIERI et al., 2009; COMPANT et al., 2010) e gerar benefícios a cultura por ser capaz de penetrar na raiz das plantas devido sua classificação como bactéria endofítica; apresentar antagonismo a agentes patogênicos; produzir fitormônios; ocorrer em todos os tipos de solo, pois possui baixa sensibilidade à variações de temperatura uma vez que ocorre em condição natural e temperatura ambiente (MULLER, 2013).

Contudo, o manejo adequado e a possível associação entre Azospirillum brasilense. Milho (Zea mays), pode resultar em incrementos de produtividade e em diminuição dos custos de produção, principalmente devido redução de aquisição de fertilizantes nitrogenados minerais segundo Bárbaro et al. (2008). Assim, objetivou-se com este estudo, avaliar produtividade de milho com a aplicação do Azospirillum brasilense e 
assim determinar a melhor dose de aplicação, responsável pelo aumento de produtividade correlacionado a relação custo de produtividade das mesmas. Contribuir para a tomada de decisão dos produtores rurais da região visando o lucro dos mesmos em relação a produção de milho.

\section{METODOLOGIA}

O experimento foi conduzido na zona rural de Monte Carmelo- MG, que apresenta as seguintes coordenadas $18^{\circ} 45^{\prime} 037^{\prime \prime}$ latitude sul, 47 $29^{\prime} 774^{\prime \prime}$ longitude oeste e uma altitude de $885 \mathrm{~m}$, no ano de 2015 . Utilizou-se um híbrido Syngenta tipo convencional, com potencial produtivo considerado excelente, ótima sanidade foliar e de grãos, além de reduzir a população de nematoides. Este híbrido é de médio investimento, facilitando assim a aquisição do mesmo pelos agricultores familiares. O solo onde o plantio foi realizado é classificado como Latossolo Vermelho, de acordo com os critérios da Empresa Brasileira de Pesquisa Agropecuária (EMBRAPA, 2015). A Tabela 01 estão as características físico químicas do solo objeto deste experimento, onde o mesmo foi analisado, seguindo a metodologia da 5a aproximação.

Tabela 1: Dados da análise de solo na profundidade de 0-20 cm.

\begin{tabular}{|c|c|c|c|c|c|c|c|c|}
\hline \multirow[t]{2}{*}{ PH } & \multirow[t]{2}{*}{$\mathrm{V}(\%)$} & Al & $\mathrm{Ca}$ & $\mathrm{Mg}$ & P meh & K & SB & M.O \\
\hline & & $\mathrm{cmolc} \mathrm{dm}^{-3}$ & dag $\mathrm{Kg}^{-1}$ & & & & & \\
\hline 5,3 & 63 & 0,08 & 3,9 & 1,6 & 12,5 & 0,25 & 5,72 & 3,3 \\
\hline
\end{tabular}

$\mathrm{pH}=$ Potencial hidrogeniônico em CaCl2; $\mathrm{V}=$ Sat. Base $\mid \mathrm{m}=$ Sat. Alumínio $\mid \mathrm{pH} \mathrm{CaCl2.2H2O} \mathrm{0,01} \mathrm{mol} \mathrm{l-1;} \mathrm{Al=} \mathrm{alumínio;} \mathrm{Ca}=\mathrm{Cálcio} ; \mathrm{Mg}=$ Magnésio; $\mathrm{P}$ meh= fósforo Mehlich -1; K= Potássio; SB=Soma das bases; M.O=Matéria orgânica.

Org.: Rezende (2015).

Esta análise teve por objetivo conhecer as características químicas do solo da área utilizada no experimento, a fim de nortear decisões no sentido de rendimento almejado, além de definir a quantidade de fertilizante a ser utilizada. Devido a heterogeneidade do solo, o experimento foi de blocos casualizados (DBC), em que se buscou comparar os efeitos de 4 tratamentos, sendo cada um deles repetido 5 vezes, totalizando 20 parcelas.

Foi utilizado o sistema de semeadura manual, sendo o milho como cultura anterior. O milho foi semeado no mês de novembro, sendo 4 linhas espaçadas de $0,7 \mathrm{~m}$, população de 4 plantas por metro linear, ou seja, 64 plantas por parcela, o que proporcionou um estande de 57.142 plantas por hectare. Seguindo as recomendações de adubação realizadas após interpretação da análise de solo, foram utilizados na semeadura $400 \mathrm{~kg} \mathrm{ha}^{-1}$ do adubo formulado 08-28-16. A aplicação de $\mathrm{N}$ em cobertura foi na forma de ureia $200 \mathrm{~kg} \mathrm{ha}^{-1}(45,0 \%$ de N). Para o controle químico de plantas daninhas foi realizado na pré-emergência, com aplicação dos princípios ativos atrazina e metolachlor, logo após a semeadura, sendo utilizado pulverizador costal manual.

As variáveis estudadas foram produtividade e aliado a isso, avaliou a relação custo de produtividade. O método de irrigação utilizada, foi o sistema convencional por aspersão, de modo a atender as necessidades hídricas da cultura, para que não houvesse déficit hídrico, durante seu ciclo vegetativo. Os tratamentos foram constituídos por Testemunha (T1 - sem inoculação por Azospirilum e adubação mineral recomendada para a cultura); inoculação com Azospirillum brasilense ( $\left.50 \mathrm{~mL} \mathrm{ha}^{-1}\right)$ e adubação recomendada para a cultura (T2); 
inoculação com Azospirillum brasilense (100 mL ha-1) e adubação recomendada para a cultura (T3); inoculação com Azospirillum brasilense (200 mL ha-1) e adubação recomendada para a cultura (T4), sendo o experimento conduzido no delineamento em blocos casualizados, com quatro tratamentos e cinco repetições, totalizando 20 unidades experimentais.

A inoculação via foliar da bactéria, bem como a adubação de cobertura foram realizadas quando as plantas estavam no estádio de desenvolvimento V6 (seis folhas expandidas), nessa fase a cultura se encontrava com 22 dias após a emergência (DAE), sendo ambos realizados no final da tarde, visando melhor eficiência da inoculação e da adubação de cobertura, visto que esse período ocorre temperaturas mais amenas.

A determinação do rendimento do milho através da massa seca de grãos foi realizada em uma área de $2 \mathrm{~m}^{2}$ de cada parcela, isolando duas linhas da extremidade (bordaduras) e $1 \mathrm{~m}$ de cada linha interna nas laterais. Resultando em 16 plantas colhidas por parcela, logo as espigas foram debulhadas com trilhadora manual, onde os grãos foram pesados em balanças analítica, para o cálculo de rendimento de produtividade.

Para a equação da produtividade, utilizamos o seguinte método: Prod= M (massa das 16 plantas) $\mathrm{P}$ (57.142 plantas ha ${ }^{-1}$ ), sendo $\mathrm{M}=$ massa $(\mathrm{kg})$ em 16 plantas e $\mathrm{P}=$ stand final da lavoura. Para a determinação da dose ótima, foi utilizada a seguinte equação: $-b /(2 * c)$, onde os parâmetros a e c são obtidos a partir do ajuste da equação, sendo a: o intercepto e c: o coeficiente angular. Na relação custo produtividade, foram consideradas custos referentes a hora máquina para a aplicação foliar, onde 1hora/ha é de $R \$ 170,00$, aquisição de insumo (bactéria) sendo a embalagem com $500 \mathrm{~mL}$ de $\mathrm{R} \$ 100,00$, valores estes referentes à região de Monte Carmelo/MG.

Os dados foram submetidos à análise de variância e posteriormente a análise de regressão, adotando-se um nível de até $5 \%$ de probabilidade. Os modelos de regressão foram escolhidos com base na significância dos coeficientes de regressão, utilizando-se o teste t no nível de até $5 \%$, no coeficiente de determinação e no processo em estudo. Assim os modelos que melhor representaram as interações, foram de regressão linear do tipo quadrática para avaliação de produtividade em relação às doses da bactéria Azospirillum brasilense e não linear modelo do tipo platô na relação entre o custo de produção e as doses da bactéria. Todas as análises foram realizadas através do programa estatístico $R$ e todos os pacotes vinculados a ele.

\section{RESULTADOS E DISCUSSÃO}

No gráfico 1 está apresentado a produtividade média da cultura de milho em função de doses do inoculante à base de bactéria Azospirillum brasilense aplicadas via foliar, pode-se observar que o aumento de doses $(\mathrm{mL})$ aplicadas à cultura, propiciou um aumento de produtividade ao se comparar com a testemunha. Isso pode ocorrer, devido a aplicabilidade do macronutriente nitrogênio e sua importância no desenvolvimento da cultura.

Por outro lado, observa-se que o tratamento utilizando $200 \mathrm{~mL} \mathrm{ha}^{-1}$ do inoculante houve um decréscimo de produtividade. Esse fato pode estar relacionado à uma possível saturação de nitrogênio 
adsorvida pelo sistema vegetativo causando assim toxidade à mesma. De acordo com Pozza et al. (2001), Deon (2007) e Negrão et al. (2010), dentre os nutrientes exercem funções específicas no metabolismo vegetal, influenciando no seu crescimento e sua produção está o nitrogênio, entretanto, quando em níveis anormais pode prejudicar a produção ocasionando estresse nutricional para a planta afetando o processo metabólico da mesma.

Campos et al. (1999) avaliando a massa seca, o teor de nitrogênio total do grão e o rendimento de grãos com corte e sem corte, concluíram que para a cultura da aveia e trigo, o $A$. brasiliense não proporcionou ganho em nenhuma das variáveis estudadas. Por outro lado, Ubert et al. (2015) estudando associação da bactéria inoculada na semente e doses de nitrogênio, verificou influência da produtividade de matéria verde de sorgo silageiro somente devido as doses de nitrogênio em cobertura.

Os mesmos autores levantam a hipótese de que doses altas de Azospirillum brasilense não influenciaram nos fatores estudados, devido o decréscimo na proporção de diazotróficos no solo em decorrência de uma supressão competitiva dos microorganismos heterotróficos, ocorrido pela influência de fertilizante mineral na associação com os microorganismos. Muller et al. (2016) também observou este efeito, onde a inoculação de Azospirillum brasilense associada à os níveis de $\mathrm{N}$ afetam significativamente a produtividade de milho.

Segundo Vogel, 2013, o uso de inoculantes, nem sempre apresentará um aumento na produção de grãos, tais variações podem ser justificadas, pois o uso da inoculação pode sofrer influências devido à variabilidade genética, estádio fenológico, características do solo, atuação de outros componentes macrobióticos, competitividade, entre outros fatores.

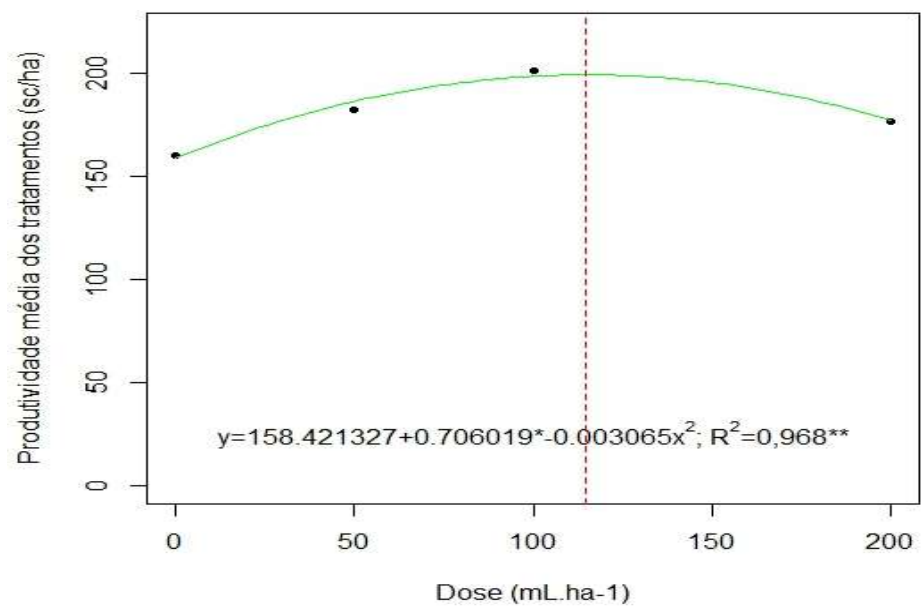

Gráfico 1: Produtividade média do milho híbrido Syngenta em função de doses aplicadas de bactéria Azospirillum brasilense via foliar e dose ótima.

O fator produtividade de grãos, ajustou-se a função quadrática, com aumento da produtividade de grãos em $25,93 \%$, quando comparado $0 \mathrm{~mL} \mathrm{ha}^{-1}$ com a melhor dose em avaliação $\left(100 \mathrm{~mL} \mathrm{ha}^{-1}\right)$. $\mathrm{O}$ coeficiente de determinação conhecido como $\mathrm{R}^{2}$ objetiva verificar se o modelo proposto é adequado ou não, e varia de 0 a 1. Ele representa a proporção da variabilidade de $Y$ explicada pelas variáveis regressoras. Assim, quanto mais próximo estiver de 1, maior é a explicação da variável resposta pelo modelo ajustado. Portanto de 
acordo com o valor do coeficiente de determinação encontrado na análise estatística, $R^{2}=0,96$, o modelo se ajustou adequadamente para os dados analisados.

Os resultados permitiram afirmar que a aplicação via foliar da bactéria $A$. brasiliense, promoveu um incremento de produtividade na cultura do milho, com aumento na produção de grãos, quando associada à utilização de adubação de plantio e de cobertura. Onde o tratamento testemunha produziu 159,93 sc/ha, e os tratamentos com inoculação 50, 100 e $200 \mathrm{~mL}$ produziu $182 \mathrm{sc} / \mathrm{ha}, 201,4 \mathrm{sc} / \mathrm{ha}$ e 176,51 sc/ha, respectivamente.

A dose ótima de inoculante calculada foi de 114,75 mL ha-1 para aplicação via foliar, sendo que esta dosagem propiciou o ápice de produtividade, atingindo o valor de $231,11 \mathrm{sc} \mathrm{ha}^{-1}$, ou seja. $71,18 \mathrm{sc} \mathrm{ha}^{-1}$ a mais ao se comparar com a testemunha. Muller et al. (2016), verificou em seu trabalho que a utilização do inoculante $A$. brasilense proporcionou um aumento médio no rendimento de $11,34 \mathrm{sc} \mathrm{ha-1} \mathrm{em} \mathrm{comparação}$ com o controle não inoculado.

De acordo com a EMBRAPA (2015), existem no Brasil produtores que já estão obtendo rendimentos de milho superiores a 200 sacas ha $^{-1}$, em manejos tradicionais, sem adição de azospirillum. A produtividade padrão nas lavouras brasileiras é bem inferior ao valor citado anteriormente, demonstrando uma grande vantagem nos sistemas de produção, a utilização de novas tecnologias, capaz de proporcionar grande variabilidade no potencial de produtividade e de rendimento por área.

No gráfico 2, está apresentado a relação custo de produtividade (RCP por Custo/Produtividade) do milho em função das doses aplicadas de bactéria Azospirillum brasilense, pode-se observar que no RCP ocorre um crescimento inicial rápido, pelo fato da testemunha possuir valor zero, e a partir da dose 50 tende um decréscimo à dose $100 \mathrm{~mL}$ onde a partir de 107 tende a estabilizar. Isso é de grande relevância, afirmando que a dose $100 \mathrm{~mL}$ do estudo é a mais indicada quanto á produtividade e proporcionando mesmo custo financeiro e maior produtividade comparado a dose $200 \mathrm{~mL}$ por exemplo.

Para o fator RCP, houve ajuste de função não linear (platô), sendo estimada uma dose de estabilidade $107 \mathrm{~mL} \mathrm{ha}{ }^{-1}$, assim a partir desse volume $(\mathrm{mL})$ ocorre a estabilização do fator, não elevando os custos de produção referente a aplicação da bactéria, ou seja, o uso de dosagem maior que este valor a relação do custo permanecerá o mesmo.

É possível verificar que a dosagem ótima encontrada anteriormente de 114,7 mL está logo após a estabilização do RCP. Diante disto recomenda-se o uso desta dose pois ela propiciou maior rendimento, trazendo assim maior ganho na produtividade, evitando excesso de aplicação de nutriente e reduzindo gastos com insumos minerais ao produtor rural.

O coeficiente de determinação obtido foi $R^{2}=0,78$, este coeficiente indica o quanto o modelo foi capaz de explicar os dados coletados. $O \mathrm{R}^{2}$ diminui caso a amplitude dos dados de variação de $\mathrm{x}$ for menor, assim podemos concluir que o coeficiente ajustado descreve a qualidade do ajuste do modelo, sendo este 0,78 explicado pela baixa variação dos dados. 


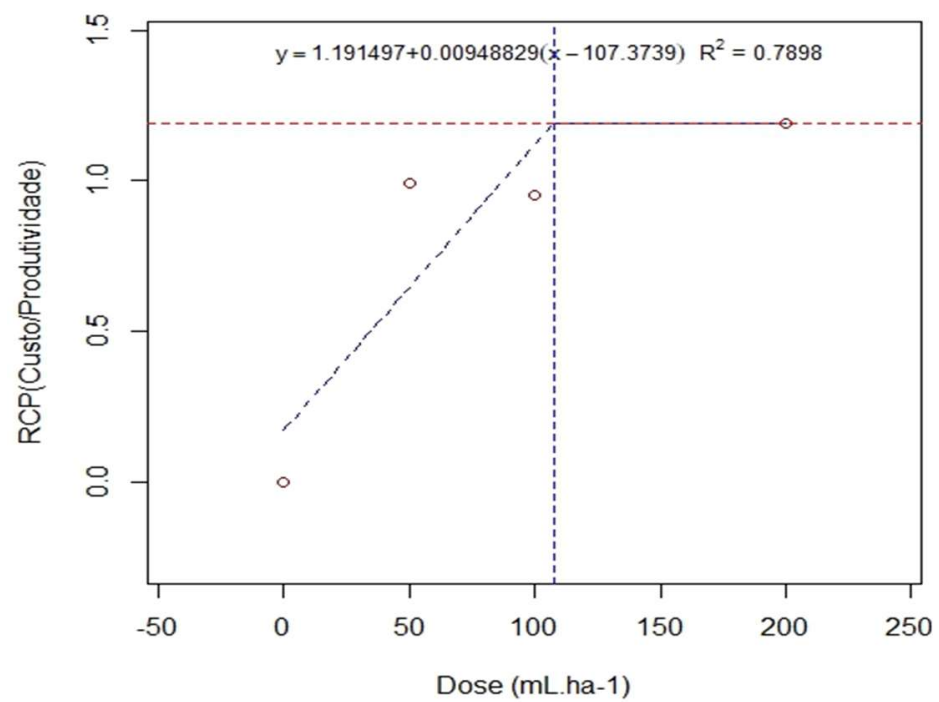

Gráfico 2: Relação custo e produtividade (RCP) por Custo/Produtividade do milho hibrido Syngenta em função das doses aplicadas de bactéria Azospirillum brasilense.

Em plantios onde não há o emprego de alta tecnologia, como a agricultura familiar os resultados dos ensaios mostram rendimentos da ordem de $3.400 \mathrm{~kg} / \mathrm{ha}$ em lavouras onde foi feita a inoculação com a aplicação de apenas $24 \mathrm{~kg}$ de nitrogênio por hectare. Já com a suplementação de $30 \mathrm{~kg}$ de nitrogênio aplicados na mesma área, conseguiu-se uma produtividade de $7.000 \mathrm{~kg} / \mathrm{ha}$. Segundo informações da Embrapa Soja, estima-se que a economia resultante desse processo possa chegar aos US\$ 2 bilhões por ano (EMBRAPA, 2015).

Para ser viável ao produtor rural, não basta dizer que as inovações tecnológicas possam proporcionar incremente na produtividade, devendo haver, de forma simultânea, estudos que relatam a viabilidade econômica e auxilie o produtor nas tomadas de decisões. A redução das margens de lucro e a falta de investimento para se obter maior produtividade pode levar à falência das pequenas propriedades rurais, contribuindo para o êxodo rural (KANEKO, 2015).

De acordo com Dalzoto et al. (2017), as informações dos custos de produção podem auxiliar o gestor rural a tomar decisões de forma eficaz em uma unidade produtiva agrícola. Nesse sentido, a análise dos custos de produção torna-se primordial para a lucratividade na produção de milho, informando ao produtor que a redução no custo de produção é uma alternativa para maximizar o lucro da atividade. Assim, a inoculação via foliar com Azospirillum brasilense é uma alternativa viável para produtores que desejam aumentar sua produtividade, produzindo milho de forma menos onerosa e ambientalmente adequada.

\section{CONCLUSÕES}

A bactéria Azospirillum brasilense, se mostrou uma alternativa viável para produtores que desejam aumentar sua produtividade e possibilitar um aumento na lucratividade com a mesma área implantada. A dose ótima de inoculante que demonstrou maior desempenho associada a adubação mineral foi de 114,75 $\mathrm{mL}$. A interação de RCP, determinou ponto de estabilidade a partir de $107 \mathrm{~mL}$, confirmando que com a dosagem ótima de 114,75 mL, leva a ser economicamente viável. Por ser tecnologia ecológica e nova, recomenda-se mais pesquisas na área, uma vez que fatores como genótipo, condições edafoclimáticas e 
estirpe da bactéria utilizada, podem ter contribuído para esse resultado. O Azospirillum brasilense demonstrou ser uma tecnologia de promoção no aumento da produção de milho de uma forma menos onerosa e ecologicamente mais limpa.

AGRADECIMENTOS: Este artigo foi realizado como parte da disciplina de Estatística Ambiental ministrada pelo Instituto Federal Goiano, como requisito do Programa de Pós-Graduação de Conservação de Recursos Naturais do Cerrado. Nossos agradecimentos a todos os professores e colaboradores que nos proporcionaram tal conhecimento.

\section{REFERÊNCIAS}

BÁRBARO, I. M.; BRANCALIÃO, S. R.; TICELLI, M.. É possível fixação biológica de nitrogênio no milho. 2008.

CALDARELLI, C. E.; BACCHI, M. R. P.. Fatores de influência no preço do milho no Brasil. Revista Nova economia, Belo Horizonte, v.22, n.1, 2012.

CAMPOS, B. H. C.; THEISEN, S.; GNATTA, V.. Inoculante 'Graminante' nas culturas de trigo e aveia. Revista Ciência Rural, Santa Maria, v.23, n.3, p.401-407, 1999.

CARVALHO, R. P.; VON PINHO, R. G.; DAVIDE, L. M. C.. Eficiência e uso do nitrogênio em híbridos experimentais de milho do programa de melhoramento da Universidade Federal do Tocantins. Revista Brasileira de Milho e Sorgo, Sete Lagoas, v.10, n.2, p.108-120, 2011.

CAVAGLIERI, L.; ORLANDO, J.; ETCHEVERRY, M.. Rhizosphere microbial community structure at different maize plant growth stages and root locations. Microbiol. Resear., v.164, p.391-399, 2009.

CONAB. Companhia Nacional de Abastecimento. Comparativo da área, produtividade e produção safra 2016/2017 e 2017/2018. 2017.

CONAB. Companhia Nacional de Abastecimento. Acompanhamento da Safra Brasileira. Grãos safra 2017/18. v.5, n.4, 2018

COMPANT, S.; CLÉMENT, C.; SESSITSCH, A.. Plant growth promoting bacteria in the for rhizo- and endosphere of plants: Their role, colonization, mechanisms involved and prospects for utilization. Soil Biol. Biochem., v.42, n.5, p.669-678, 2010.

COSTA, N. L.; PAULINO, V. T.; COSTA, R. S. C.; ARAÚJO PEREIRA, R. G.; TOWNSEND, C. R.; MAGALHES, J. A.. Efeito de micorrizas arbusculares sobre o crescimento e nutrição mineral de Brachiaria brizantha cv. Marandu. Revista Ciência Animal Brasileira, v.13, n.4, p.406-411.

DALZOTTO, A. F.; LOPES, F. A.; SOUZA, A. R. L.; SILVA, L. X.. Relação entre os custos de produção e o preço de mercado do milho. Custos e @gronegócio online, v.13, n.2, p.448469, 2017.

DEON, M. D.. Crescimento e nutrição mineral da soja submetida a excesso de $\mathrm{P}, \mathrm{S}, \mathrm{K}, \mathrm{Ca}$ e $\mathrm{Mg}$ em solução nutritiva. Dissertação (Mestrado em solos e nutrição de plantas) - Universidade de São Paulo Piracicaba, 2007.

DOTTO, A. P.; LANA, M. C.; STEINER, F.; FRANDOLOSO, J. F. Produtividade do milho em resposta à inoculação com Herbaspirillum seropedicae sob diferentes níveis de nitrogênio. Revista Brasileira de Ciências Agrárias, Recife, v.5, n.3, p.376-382, 2010.

EMBRAPA. Empresa Brasileira de Pesquisa Agropecuária. Cultivo do Milho. Revista Embrapa Milho e Sorgo. 9 Ed. 2015

GROSS, M. R.; VON PINHO, R. G.; BRITO, A. H.. Adubação nitrogenada, densidade de semeadura e espaçamento entre fileiras na cultura do milho em sistema plantio direto.

Revista Ciência e Agrotecnologia, Lavras, v.30, n.3, p.387393, 2006.

KANEKO, F. H.; SABUNDJIAN, M. T.; ARF, O.; FERREIRA, J. P.; GITTI, D. C.; NASCIMENTO, V.; LEAL, A. J. F.. Análise econômica do milho em função da inoculação com azospirillum, fontes e doses de $\mathrm{n}$ em cerrado de baixa altitude. Revista Brasileira de Milho e Sorgo, Sete Lagoas v.14, n.1, p.23-37, 2015.

MDIC. Ministério da Indústria Comércio Exterior e Serviços. Balança comercial: Janeiro-dezembro 2017. 2018.

MEIRA, F. A.; BUZETTI, S.; ANDREOTTI, M.; ARF, O.; SÁ, M. E.; ANDRADE, J. A. C.. Fontes e épocas de aplicação do nitrogênio na cultura do milho irrigado. Semina: Ciências Agrárias, Londrina, v.30, n.2, p.275-284, 2009.

MULLER, T. M.. Inoculação de Azospirillum brasilense associadas a $\mathbf{n}$ de adubação nitrogenada e o uso de bioestimulante vegetal na cultura do milho. Dissertação (Mestrado em Agronomia) - Universidade Estadual do Centro-Oeste, Guarapuava, 2013.

MULLER, T. M.; SANDINI, I. E.; RODRIGUES, J. D.; NOVAKOWISKI, J. H.; BASI, S.; KAMINSKI, T. H.. Combination of inoculation methods of Azospirilum brasilense with broadcasting of nitrogen fertilizer increases corn yield. Revista Ciências Rural, Santa Maria, v.46, n.2, p.210-215, 2016. 
NEGRÃO, R. G.; FLORA, A. P.; BRUGGER, B. P.; SANTOS, F. R.; COUTO, F. P.. Estresse nutricional em plantas. 2010.

POZZA, A. A. A.; MARTINEZ, H. E. P.; CAIXETA, L. S. C.; CARDOSO, A. A.; ZAMBOLIM, L.; POZZA, E. A.. Influência da nutrição mineral na intensidade da mancha-de-olho-pardo em mudas de cafeeiro. Pesquisa Agropecuária Brasileira, Brasília, v.36, n.1, p.53-60, 2001.

ROMUALDO, L. M.; LUZ, P. H. C.; BAESSO, M. M.; DEVECHIO, F. F. S.; APOSTA, J. A.. Índices espectrais para identificação de deficiência de nitrogênio em milho. Revista Ciência Agronômica, v.49, n.2, p.183-191, 2018.

SOUZA, H. A.; CAVALCANTE, A. C. R.; POMPEU, R. C. F. F.; TONUCCl, R. G.; MODESTO, V. C.; NATALE, W.. Avaliação da eficiência agronômica de fontes e doses de nitrogênio na cultura do milho em região Semiárida. In: FERTBIO. Anais. Maceió, 2012.

SOUZA, C. F.. Desempenho agronômico e eficiência de utilização de nitrogênio por cultivares de milho. Tese
(Doutorado em Fitotecnia) - Universidade Federal Rural do Semi-Árido, Mossoró, 2017.

UBERT, I. P.; SOLIGO, S. C.. Associação de Azospirillum brazilense a doses de nitrogênio na cultura do sorgo silageiro. Revista Enciclopédia Biosfera, Goiânia, v.11, n.21, p.220-229, 2015.

VALE, H. S.; SILVA, E. S.; CARMO, I. L. G. S.; NETO, J. L. L. M.; SILVA, A. P.; MEDEIROS, R. D.. Doses de nitrogênio na produção de milho cultivado em sucessão ao meloeiro no Cerrado de Roraima. In: CONGRESSO BRASILEIRO DE CIÊNCIAS DO SOLO, 35. Anais. Natal, 2015. p.1-4.

VON PINHO, R. G.; BORGES, I. D.; PEREIRA, J. L. A. R.; REIS, M. C. D.. Marcha de absorção de macronutrientes e acúmulo de matéria seca em milho. 2009. Revista Brasileira de Milho e Sorgo, v.8, n.2, p.157-173, 2009.

VOGEL, G. F.; BICHEL, A.; MARTINKOSKI, L.; MARTINS, P. J. Desempenho Agronômico de Azospirillum Brasilense na Cultura do Arroz: Uma Revisão. Revista em Agronegócios e Meio Ambiente, v.6, n.3, p.567-578, 2013.

A CBPC - Companhia Brasileira de Produção Científica (CNPJ: 11.221.422/0001-03) detém os direitos materiais desta publicação. Os direitos referem-se à publicação do trabalho em qualquer parte do mundo, incluindo os direitos às renovações, expansões e disseminações da contribuição, bem como outros direitos subsidiários. Todos os trabalhos publicados eletronicamente poderão posteriormente ser publicados em coletâneas impressas sob coordenação da Sustenere Publishing, da Companhia Brasileira de Produção Científica e seus parceiros autorizados. Os (as) autores (as) preservam os direitos autorais, mas não têm permissão para a publicação da contribuição em outro meio, impresso ou digital, em português ou em tradução. 